\title{
Месторождения стратегических металлов арктического региона
}

\author{
Волков А.В., Бортников Н.С., Лобанов К.В., Галямов А.Л., Чичеров М.В. \\ Институт геологии рудных месторождений, петрографии, минералогии и геохимии Российской \\ Академии наук (ИГЕМ РАН), Москва
}

Аннотация. В экономике арктических стран минерально-сырьевой сектор занимает одно из центральных мест, что обусловливает высокую значимость состояния минерально-сырьевой базы (МСБ) и динамики ее развития. В глобальной перспективе наметилась устойчивая тенденция развития ресурсов стратегических металлов в Циркум-Арктической зоне. Российская Арктика - крупнейший поставщик этих металлов на внутренний и внешний рынок. Для разработки направлений геологоразведочных и научно-исследовательских работ большой интерес представляет сравнительный анализ тенденций развития МСБ стратегических металлов арктической зоны России и других стран. В статье проанализирован и обобщен представительный материал, позволяющий оценить развитие арктических ресурсов стратегических металлов в глобальной перспективе. Показано, что минерально-сырьевой потенциал Арктического циркумполярного металлогенического пояса в основном определяется наличием крупных и уникальных месторождений, цветных, благородных и редких металлов. Сделаны выводы о перспективных для промышленности типах месторождений стратегических видов минерального сырья в Арктической зоне Российской Федерации.

Ключевые слова: Арктика, Циркум-Арктическая зона, месторождения, стратегические металлы, металлогения

\section{Deposits of strategic metals in the Arctic region}

\author{
Volkov A. V., Bortnikov N.S., Lobanov K. V., Galyamov A. L., Chicherov M.V. \\ Institute of Geology of Ore Deposits, Petrography, Mineralogy and Geochemistry, \\ RAS (Moscow, Russian Federation)
}

\begin{abstract}
In the economy of the Arctic countries, the mineral raw material sector plays one of key roles, which determines the high importance of the state of the mineral resource base (MRB) and the dynamics of its development. In the global perspective, there has been a steady trend in the development of resources of strategic metals in the CircumArctic zone. The Russian Arctic is the largest supplier of these metals to the domestic and foreign markets. To develop areas of exploration and research, a comparative analysis of trends in the development of MRB of strategic metals of the Arctic zone of Russia and other countries is important. The article analyzes and summarizes the representative material to assess the development of Arctic resources of strategic metals in the global perspective. It is shown that the mineral potential of the Arctic circumpolar metallogenic belt is mainly determined by the presence of large and unique deposits, non-ferrous, precious and rare metals. Conclusions are drawn about the types of deposits of strategic mineral raw materials in the Arctic zone of the Russian Federation that are promising for the industry.
\end{abstract}

Keywords: Arctic, Circum-Arctic Belt, deposits, strategic metals, metallogeny

\section{Введение}

Арктическая зона - регион исключительного значения для экономики, национальной безопасности и внешнеэкономических связей Российской Федерации. Здесь находится развитая инфраструктура морских коммуникаций. Эффективное включение минеральных ресурсов этой зоны в процессы развития России требуют поворота к идеологии и практике устойчивого развития в сочетании с современными политическими, федеративными, социально-экономическими и организационными подходами.

Россия занимает одно из ведущих мест в мире среди арктических стран - производителей минерального сырья. Кроме громадных запасов нефтегазового сырья, в арктических регионах России находится около 10 \% активных мировых запасов никеля, около 19 \% МПГ, 10 \% титана, более 3 \%, цинка, кобальта, золота и серебра. При этом детальные геологические исследования выполнены лишь для небольшой части Российской Арктики, большая часть территории которой (около 4 млн. км²) остается очень слабо изученной в силу трудной доступности. 
В Циркум-Арктической зоне выделяют три крупных сектора: Североамериканский, Скандинавский и Российский. Территория Циркум-Арктической зоны и основные месторождения, рассматриваемые в статье, показаны на карте (рис. 1).

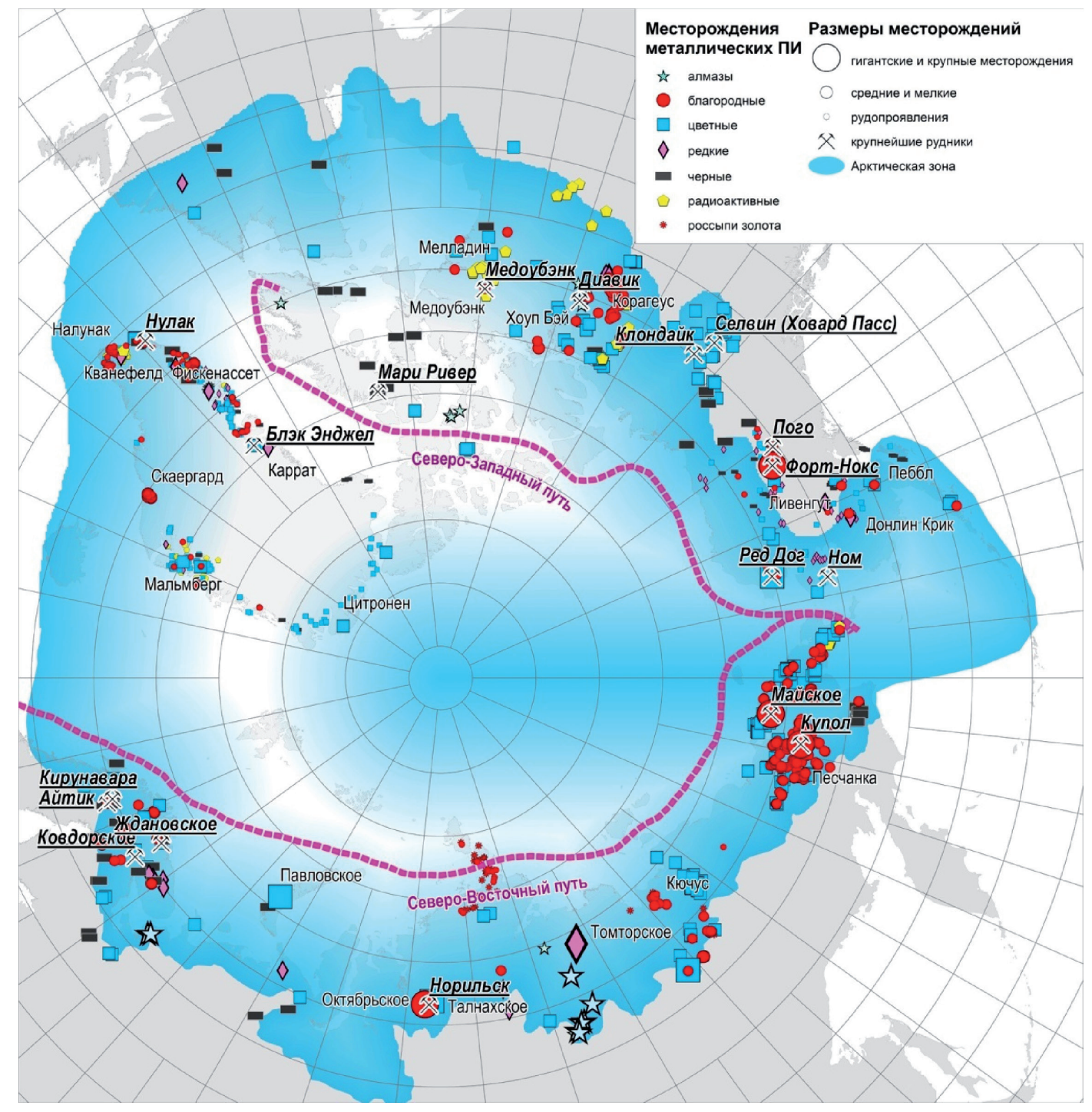

Рис. 1. Положение крупных и суперкрупных месторождений твердых полезных ископаемых в циркум-арктической зоне.

Fig. 1. The position of large and super-large deposits of solid minerals in the Circum-Arctic zone.

\section{Металлогения Арктики}

Литосфера Арктической зоны включает древние щиты (Балтийский, Анабарский и Канадский), перекрывающие их позднедокембрийский и палеозойский платформенные чехлы, складчатые орогенные пояса (Каледонский, Уральский, Таймырский, Тиманский, Иннуитский, ВерхояноЧукотский и Северной Аляски), разделяющие древние платформы (Восточно-Европейскую, Сибирскую и Северо-Американскую), внутриплитные магматические провинции различных эпох от раннего докембрия до кайнозоя и мезозойские вулканогенные пояса (Олойский, Уяндино-Ясаченский и Охотско-Чукотский).

В пределах докембрийских щитов расположены крупнейшие месторождения железа, золота, хрома, алмазов, платиноидов, никеля, меди, полиметаллов, ванадия и урана. Щиты могут рассматриваться в качестве наиболее перспективных арктических регионов на открытие новых крупных 
месторождений. Периферийные части щитов, как правило, были подвержены последующей террейновой аккреции, приведшей к росту кратонов и в ряде случаев к унаследованному развитию минерализации и, таким образом, также весьма перспективны на обнаружение крупных месторождений, имеющих близкую металлогеническую специализацию.

В связи со сложным сочетанием в Арктической мегапровинции докембрийско-палеозойскораннемезозойскими геоструктур континента, металлогения российской Арктической зоны носит секторальный характер (Сафонов, 2010).

В Восточно-Европейской секторе в границах Балтийского щита и его обрамления выявлены крупные месторождения стратегического сырья: титана, меди, никеля, платиноидов и РЗЭ, связанные с проявлениями щелочно-ультраосновного магматизма в эпоху 390-350 млн. лет (Кольская металлогеническая провинция).

Тимано-полярноуральский сектор содержит средние по масштабам Саурейское (свинцовоцинковое) и Новогоднее Манто (золото-скарновое) месторождения. На острове Новая Земля известны палеозойские свинцово-цинковые и медные рудопроявления различных типов. Наибольший интерес представляет значительное по запасам и ресурсам Павловское свинцово-цинковое месторождение.

Металлогения Восточно-Сибирского сектора связана с пермско-триасовым этапом (Хаин и др., 2009), в который формировались комплексные месторождения $\mathrm{Cu}, \mathrm{Ni}, \mathrm{Co}, \mathrm{Pt}, \mathrm{Pd}, \mathrm{Au}, \mathrm{Ag}$, и $\mathrm{Te}$ Норильского района (табл. 1). Существенным золоторудным и россыпным потенциалом обладает п-ов Таймыр и острова архипелага Северная Земля (Проскурнин, 2014). На Анабарском щите выявлено месторождение РЗЭ мирового класса Томтор. В различных районах щита прогнозируются месторождения урана «типа несогласия» (Молчанов и др., 2006). На территории щита и прилегающих площадях известны проявления россыпного золота, платиноидов, алмазов.

В мезозойский этап образованы основные месторождения Верхояно-Чукотского арктического сектора. Золоторудные, оловорудные и полиметаллические месторождения связаны с вулканитами и интрузиями альб-позднемелового возраста, относящихся к Охотско-Чукотскому окраинноконтинентальному вулканическому поясу (ОЧВП) (Волков и др., 2006). В пределах сектора выявлены многочисленные золотые, оловянные и олово-вольфрамовые россыпи как континентального, так и прибрежно-морского генезиса (в том числе и шельфовые, находящиеся под уровнем современного моря).

\section{Стратегические месторождения Арктики}

Арктическая МСБ стратегических металлов, рассматриваемая в данном разделе, представлена рудными месторождениями 14 видов полезных ископаемых (табл. 1), запасы и ресурсы которых учтены государственным балансом РФ или оценены в соответствии с международными стандартами (российские ресурсы представлены только категорией $\mathrm{P}_{1}$ ). В Арктической зоне известно 111 месторождений стратегических металлов, находящихся на различных стадиях освоения, в том числе российских - 44, США (Аляска) - 19, канадских - 23, гренландских -8 , норвежских - 6, шведских - 9, финских - 3 (табл. 2). На 25 Арктических месторождениях действуют рудники, 43 месторождение относится к потенциально промышленным объектам, часть из этой группы подготавливается к освоению, а на других завершается детальная разведка, еще 44 объекта имеют только ресурсный потенциал, для перевода которого в запасы необходима постановка детальных ГРР. В Арктике насчитывается (по наиболее значимому металлу): $43 \mathrm{Au}, 16 \mathrm{Zn}, 11 \mathrm{Sn}, 8 \mathrm{Cu}, 6 \mathrm{Ni}, 5 \mathrm{~W}, 4 \mathrm{PGE}, 2 \mathrm{Mo}$, $4 \mathrm{Ti}, 3 \mathrm{P} 3 Э, 2 \mathrm{U}, 1 \mathrm{Zr}$, и $1 \mathrm{~Pb}$ месторождений (табл. 2). Многие из арктических месторождений - комплексные, содержат значительное количество сопутствующих, потенциально извлекаемых металлов. Месторождения в российском секторе составляют значительную (а по $\mathrm{Ni}, \mathrm{Cu}, \mathrm{Co}, \mathrm{W}, \mathrm{Zr}, \mathrm{Ag}$, $\mathrm{Pt}+\mathrm{Pd}$ - преобладающую) часть запасов минеральных ресурсов арктической зоны (табл. 3).

В Арктике также имеются крупные месторождения редкоземельных металлов. В Мурманской области расположено комплексное ( $\mathrm{Ta}, \mathrm{Nb}, \mathrm{P} 3 \mathrm{M})$ Ловозерское месторождение - единственное в России, из руд которого РЗМ извлекают в концентраты (около 7 тыс. т в год) (Государственный..., 2014). 
Таблица 1. Доля Арктики в мировых запасах и добыче по основным видам твердых полезных ископаемых.

Table 1. Share of the Arctic in world reserves and production by major solid minerals.

\begin{tabular}{|c|c|c|}
\hline Полезные ископаемые & Доля в мировых запасах (\%) & Доля в глобальной добыче (\%) \\
\hline Никель & 10.15 & 14.25 \\
\hline Кобальт & 3,3 & 11 \\
\hline Медь & 0.48 & 0.6 \\
\hline Цинк & 3.8 & 4.64 \\
\hline Свинец & 2.69 & 2.37 \\
\hline Вольфрам & 0.44 & 4.03 \\
\hline Титан & 10.52 & 4.84 \\
\hline Циркон & 1.05 & 1.76 \\
\hline Золото & 3.25 & 2.87 \\
\hline Серебро & 3.72 & 4.19 \\
\hline Платина & $18.93^{1}$ & 15.33 \\
\hline Палладий & & 41.24 \\
\hline
\end{tabular}

Источник: Mineral commodity summary, 2013

Таблица. 2 Распределение месторождений по металлам и по странам.

Table 2. Distribution of deposits by metals and by countries.

\begin{tabular}{|l|c|c|c|c|c|c|c|}
\hline \multirow{2}{*}{ Металлы } & \multicolumn{7}{|c|}{ Арктические страны } \\
\cline { 2 - 9 } & Россия & США & Канада & Гренландия & Норвегия & Швеция & Финляндия \\
\hline Никель & 3 & & & & & & 1 \\
\hline Медь & 3 & 5 & 2 & & & 3 & \\
\hline Цинк & 1 & 4 & 6 & 3 & 2 & 2 & \\
\hline Свинец & 1 & & & & & & \\
\hline Олово & 11 & & & & & & \\
\hline Вольфрам & 4 & & 2 & & & & \\
\hline Молибден & & & & 1 & 1 & & \\
\hline Титан & 2 & & & & 2 & & 1 \\
\hline Циркон & 1 & & & & & & \\
\hline Золото & 14 & 10 & 12 & 1 & 1 & & \\
\hline МПГ & 2 & & & 1 & 6 & 9 & 3 \\
\hline Всего & 42 & 19 & 22 & 6 & & & \\
\hline
\end{tabular}

Таблица 3. Доля российских запасов и добычи в Арктике и в РФ в целом.

Table 3. Share of Russian reserves and production in the Arctic and Russia as a whole.

\begin{tabular}{|c|c|c|c|c|}
\hline \multirow{2}{*}{ Полезные ископаемые } & \multicolumn{2}{|c|}{ Доля (\%) в Арктике } & \multicolumn{2}{c|}{ Доля в РФ (\%) } \\
\cline { 2 - 5 } & запасах & добыче & запасах & добыче \\
\hline Никель & 97 & 97 & 70.5 & 83.33 \\
\hline Медь & 48.4 & 81.86 & 4.05 & 54.37 \\
\hline Кобальт & 99 & 99 & 75 & 85 \\
\hline Цинк & 13.15 & & 3.25 & \\
\hline Свинец & 17.97 & & 4.28 & \\
\hline Олово & 100 & & 50.23 & \\
\hline Вольфрам & 43.1 & & 5.11 & \\
\hline Молибден & 2.36 & & 4.7 & \\
\hline Титан & 30.9 & & 8.75 & \\
\hline Циркон & 99 & 100 & 5.17 & 98 \\
\hline Золото & 23.3 & 34.2 & 11.72 & 9.75 \\
\hline Серебро & 52.77 & 29.16 & 11.16 & 13 \\
\hline Платина+Палладий & 99.55 & 98.84 & 94.60 & 95.37 \\
\hline
\end{tabular}


Разведанные запасы РЗМ Ловозерского месторождения, составляют более 25 \% российских; среднее содержание суммы оксидов редких земель в рудах $-1.12 \%$. В рудах месторождений Хибинской группы, разрабатываемых на фосфор, содержится более $40 \%$ российских запасов РЗМ, которые из получаемого апатитового концентрата не извлекаются (Государственный..., 2014). В мире эта группа уникальных месторождений не имеет аналогов.

В арктической зоне Якутии находится уникальное Томторское месторождение. Основные компоненты руд - ниобий, РЗМ и скандий. Руды отличаются очень высоким содержанием редких земель - $7.98 \% \sum \mathrm{TR}_{2} \mathrm{O}_{3}$ (Государственный..., 2014).

\section{Заключение}

Несмотря на то, что обширная территория Циркум-Арктической зоны обладает крупными месторождениями стратегических металлов значительная часть Арктической зоны остается слабо изученной и требует постановки прогнозно-поисковых работ в первую очередь вдоль 200 км зоны арктического побережья и крупных рек, впадающих в океан. В последние годы интерес горнодобывающей промышленности к арктическим ресурсам заметно растет, что выражается в оживлении ГРР в новых районах (Чукотка, Таймыр, Аляска, Нунавут, Гренландия), и сопровождается ростом объемов добычи, прежде всего, золота и меди, а также возобновлением добычи свинцово-цинковых и вольфрамовых руд на ранее законсервированных месторождениях. Перспективы освоения арктических месторождений стратегических металлов, кроме масштаба и богатства руд, во многом определяются близостью к северному морскому пути и к судоходным рекам, что значительно повышает рентабельность работы рудников за счет использования водного транспорта.

В новых, неосвоенных районах Циркум-Арктической зоне наиболее интересны в промышленном плане: месторождения цветных металлов $\mathrm{Cu}-\mathrm{Ni}-\mathrm{Co}-(\mathrm{PGE})$ (Норильского типа); крупные месторождения $\mathrm{Pb}-\mathrm{Zn}-\mathrm{Ag}$ типа «SEDEX» (примеры, Ред Дог, Павловское) и колчеданнополиметаллические месторождения (VMS), обогащенные золотом и серебром (Грин Крик); месторождения благородных металлов: бонанцевые эпитермальные Au-Ag Ls-типа месторождения (Купол, Двойной и др.), золото-сульфидные вкрапленные месторождения (Майское, Донлин), месторождения золота, связанные с интрузивами гранитоидов (Форт Нокс, Пого, Кенсингтон), золотокварцевые месторождения в турбедитах (Джуно, Каральвеем), месторождения золота в зеленокаменных поясах (Медувбанк и др.), а также крупные россыпи золота и МПГ (аллювиальные и прибрежно-морские); богатые $\mathrm{Cu}-\mathrm{Mo}, \mathrm{Cu}-\mathrm{Au}, \mathrm{Mo}-\mathrm{W}, \mathrm{Sn}-\mathrm{In}$ месторождения.

В старопромышленных или близким к таковым арктических регионах (Скандинавские страны, Мурманская область, Норильский район) в инвестиционном плане интересны те же месторождения, что и в неполярных районах. Примерами служат бедное $\mathrm{Cu}-\mathrm{Au}$-порфировое месторождение Айтик (Швеция), титановое месторождение Телнес (Норвегия), бедное месторождение золота Форт Нокс (Аляска) и др.

Работа выполнена при финансовой поддержке РФФИ (грант No 18-05-70001) «Изучение геологических и геодинамических обстановок формирования крупных месторождений стратегических металлов Арктической зоны России: выводы для прогнозирования и поисков новых месторождений».

\section{Литература}

1. Волков А.В., Гончаров В.И., Сидоров А.А. Месторождения золота и серебра Чукотки. Магадан: СВКНИИ ДВО РАН. 2006.

2. Государственный доклад «О состоянии и использовании минерально-сырьевых ресурсов Российской Федерации в 2012 год» / Гл. ред. Д.Г. Хромов. М.: ИАЦ «Минерал». 2014.

3. Молчанов А.В., Коваль С.Г., Ходжаев Д.К. и др. Перспективы выявления высокорентабельных урановых и комплексных месторождений «типа несогласия» на Анабарском щите // Руды и металлы. 2006. № 6. С. 5-15.

4. Проскурнин В.Ф. Минерагенический анализ Таймыро-Североземельского региона и оценка его золотоносного потенциала // Автореф.докт.дисс. 2013. 40 p.

5. Сафонов Ю.Г. Состояние и рациональные направления освоения рудных ресурсов российской Арктики // Геология и геофизика. 2010. Т. 51. № 1. С. 142-152.

6. Хаин В.Е., Полякова И.Д., Филатова Н.И. Тектоника и нефтегазоносность Восточной Арктики // Геология и геофизика. 2009. Т. 50 № 4. С. 443-460.

7. Mineral commodity summary 2013. U.S. Geological Survey. 2014. 198 p. 